\title{
A PRODUÇÃO DE AGROCOMBUSTÍVEIS E O ENLAÇO COM A SEGURANÇA E SOBERANIA ALIMENTAR
}

\section{AGROFUELS PRODUCTION AND ITS RELATION WITH FOOD SECURITY AND FOOD SOVEREIGNTY}

\author{
${ }^{1}$ Caroline Vargas Barbosa \\ ${ }^{2}$ Luciana Ramos Jordão
}

\section{RESUMO}

O artigo trata da produção de agrocombustíveis como razão da intensificação da dissociação do indivíduo com a terra e o meio ambiente e a asseveração da problemática da segurança e soberania alimentar. Por meio do método dedutivo, procurar-se-á demonstrar que o rompimento da relação do homem com o meio ambiente é uma face do capitalismo que determina a exploração e produção maximizada da terra em busca de lucros e como isso interfere na segurança e soberania alimentar nacional. Para tanto, primeiramente trata-se da relação do indivíduo com a terra, meio ambiente, economia, Estado e política, concentrandose na temática da centralidade de direitos fundamentais que abarcam o meio ambiente e o indivíduo como vertente de reconhecimento e (des)envolvimento material de direitos fundamentais. No segundo momento, traz-se o panorama da produção de agrocombustíveis e sua relação com a segurança e soberania alimentar. Por fim, apresentam-se conceitos e diferenças entre os institutos de soberania alimentar e segurança alimentar para que seja palpável a construção de uma realidade que as assegure frente a agricultura familiar e a policultura mesmo que em vertente oposta da determinada pelo capitalismo e assegurada pelo Estado no que se refere a produção e exploração extensiva do meio ambiente. E com isso, conclui-se que para a garantia de direitos fundamentais é necessário o indivíduo reconhecerse com o meio ambiente a fim de construir uma significativa postura Estatal enquanto política econômica que favoreça a soberania e segurança alimentar.

Palavras-chave: Direito agrário, Direitos fundamentais, Soberania alimentar, Segurança alimentar, Agrocombustíveis

\footnotetext{
${ }^{1}$ Mestre em Direito Agrário pela Universidade Federal de Goiás - UFG, Goiás (Brasil). Professor Adjunto da Faculdade Cambury de Goiânia, Goiás (Brasil). E-mail: advcarol.vargas@ gmail.com

${ }^{2}$ Mestre em Direito Agrário pela Universidade Federal de Goiás - UFG, Goiás (Brasil). Pesquisadora da Universidade Federal de Goiás - UFG, Goiás (Brasil). E-mail: 1r.jordao@me.com
} 


\begin{abstract}
The article discusses agrofuels production as a reason for increasing the dissociation between the human being, the land and the environment, considering the issues involving food security and food sovereignty. By using the deductive method, it aims to demonstrate that the growing distance between men and land is one of the results determined by capitalism, which is based on exploitation and maximized land production in order to obtain profit, interfering thereas in national food security and food sovereignty. Thus, it first deals with the relation between the human being, land, the environment, economy, State and politics, focusing on environmental human rights protagonism such as side for recognizing and developing /enveloping fundamental rights material. Secondly, it brings agrofuels production scenario and its relation with food security and sovereignty. Finally, it concepts food security and food sovereignty, establishing its differences in order to permit the build up a solid reality that is also able to secure their implement in an economy of family polycultural basis even if there is an opposite side oriented by capitalism and protected by State, specially in which concerns to productions and environmental excessive exploitation. The article concludes that to secure fundamental rights the being needs to recognize oneself as part of the environment in order to develop a significant State behavior which will reflect on economical politics that favors food security and food sovereignty.
\end{abstract}

Keywords: Agrarian law, Fundamental rights, Food sovereignty, Food security, Agrofuels 


\section{INTRODUÇÃO}

A transformação da terra e do trabalho como mercadoria no capitalismo é regulada pelo ordenamento incorrendo da falta de identificação do indivíduo consigo mesmo e com a terra como meio essencial de sobrevivência e desenvolvimento singular. E, nessa ausência de identificação, emergem as formas opressoras e marginalizadoras do capitalismo asseverando a produção e exploração intensiva em troca de cifras que, não raras vezes, não chegam ao trabalhador que impôs seu trabalho à terra. Com o aumento da população mundial, a evidente degradação dos recursos naturais, e a multiplicação das teorias acerca da impossibilidade de manutenção do sistema produtivo contemporâneo, a garantia de produção de alimentos para todos os habitantes do planeta não poderia deixar de representar preocupação. No entanto, para que se possa produzir gêneros alimentícios é indispensável que haja espaço e recursos disponíveis.

Entre 1990 e 2005, observou-se crescimento anual de 2,7 milhões de hectares de área plantada no planeta. A expansão agrícola pode ser explicada não apenas pelo incremento populacional, mas também pelo aumento dos rendimentos, da urbanização e da demanda por agrocombustíveis (THE WORLD BANK, 2010, p. 7). Contudo, mesmo diante do aumento da área plantada, sabe-se que ainda é alta quantidade de pessoas que passam fome. O temor de que haja problemas relacionados à oferta de alimentos em razão do esgotamento da capacidade produtiva do planeta gera, por si, a problematização persistente neste trabalho. Por meio do método dedutivo, busca-se pautar a contribuição da produção de agrocombustíveis para a dissociação do homem ao meio ambiente e a consequente intensificação da crise alimentar.

Desse modo, no primeiro momento trata-se da dissociação do homem com a terra e o meio ambiente e de como o capitalismo se utiliza disto, com o aval do Estado por meio de políticas-econômicas. Tem-se motivo determinante para asseverar a busca pela justiça social ante a ineficácia de direitos fundamentais, balizados em uma igualdade formal que jamais alcança a materialidade aos indivíduos. Posteriormente, traz-se à baila, o panorama da produção de agrocombustíveis como uma faceta do capitalismo, e seu laço com os conceitos de segurança e soberania alimentar. Por fim, identificam-se as características de cada instituto para que se evidencie sua distinção, embora haja uma complementação simbiótica entre ambos. 


\subsection{O Des(envolvimento) do Indíviduo com a Terra e o Meio Ambiente}

O capitalismo transforma a terra em mercadoria fictícia e impõe um sistema de mercado baseado no trabalhador assalariado. A terra e o meio ambiente como um direito absoluto caracterizada pelo Liberalismo sofrem restrições intervencionistas por meio do Estado, para que regule seu mercado e condicione os indivíduos, proprietários ou não, a um mesmo fim: o da geração de renda (lucro). No entanto, a terra comporta características singulares de geração de renda: pela produção, como reserva de mercado, hipoteca ou venda. Em razão destas singularidades, combinadas com uma contenção social, o Direito supre a regularização de mercado por meio de leis e politicas públicas ou estatais de incentivo econômico e proteção social.

O homem, neste aspecto, tem sua relação com a terra de duas formas: a primeira, coerente com o desenvolvimento capitalista, de onde retira da terra sua fonte de lucro; a segunda, como uma relação vital de manutenção da vida. Nesta segunda acepção, fala-se no vínculo primitivo do homem com a natureza, e do emprego do trabalho como meio de subsistência, respeitando a terra e usando-a de acordo com o ciclo vital, emanando pelas ordens ambientais.

Mas em que momento, homem, capitalismo e terra conseguem encontrar a congruência? As antagônicas prospecções do uso e utilidade da terra, resultam em um processo de exclusão e negligência de direitos. Enquanto se assevera a proteção a propriedade privada, excluem-se os que não a tem. Da mesma forma, a proteção socioambiental da terra, é considerada insuficiente para o capitalismo e o Estado, que não enxergam a policultura rentável ao desenvolvimento econômico, embora se entenda ser primordial ao reconhecimento de direitos sociais e fundamentais. O confronto de ideais, supera as normativas jurídicas ou decisões estatais, e encontra valores éticos, sociais, históricos e ideológicos. A acumulação material fica dissociada de valores morais e das necessidades humanas condicionais ao indivíduo, como por exemplo o bem estar social, e transmuta qualidades em produtos no mercado de trabalho (GIDDENS, 2005, p. 298).

Nesse aspecto, é necessária uma ruptura orgânica da sociedade, para impor o trabalho como medida. O padrão cultural anterior não era do ganho maximizado de lucros para individualidades, era o da subsistência. Quando os indivíduos da sociedade são oprimidos, e retiram-lhe o meio de subsistência (terra), o trabalho torna-se a fonte singular de (des)envolvimento social. Surge a premência de uma análise do homem como todo, não 
somente voltado à expropriação do trabalho. Um conjunto de características que resultem em uma independência mínima de direitos, por meio de método de abordagem social. Compreendese desta maneira, a rejeição à economia e a política impostas que determinam como fim o que o homem procura atingir, não para si, mas para o sistema (POLANYI, 2012, p. 183-189).

O capitalismo primeiramente desconstrói as relações sociais, para relações de dominação balizadas no poderio econômico. E, quando voltado à agricultura, agrega valor a terra, pela valorização mercadológica constante fundada da produtividade e na renda gerada. $\mathrm{Ou}$ seja, em troca da alta produtividade, exclui-se e se dissocia a propriedade da terra e o meio ambiente do trabalhador rural, conferindo a razão de tudo ao capital (VERGOPOULOS, 1986, p. 85-88). O semblante mais claro do capitalismo está no campo, no qual aplica o desenvolvimento intensivo e extensivo voltado ao capital, caracterizado pela proletarização do trabalhador rural (subordinação do trabalho ao capital) e modernização das atividades agropecuárias. Outrossim, o campo, na visão estatal, é condicionado à alimentação do setor industrial e não para o bem estar do trabalhador rural, o que é evidenciado pelas políticas públicas agrícolas (IANNI, 1981, p. 89-108).

A terra, como outrora mencionado, é um elemento da natureza e fundamental, portanto, à vida humana. A terra aborda, então, interesse econômico, político e social. Social, na medida que intrínseco ao homem, econômico, pois como mercadoria para o capitalismo vincula a geração de renda e pelo Estado na regulação do mercado, portanto, evidenciada a vertente política. Nesse sentido:

\footnotetext{
A função econômica é apenas uma entre as muitas funções vitais da terra. Esta dá estabilidade à vida do homem; é o local da sua habitação, é a condição da sua segurança física, são as paisagens e as estacoes do ano. Imaginar a vida do homem sem a terra é o mesmo que imaginá-lo nascendo sem mãos e pés. E, no entanto, separa a terra do homem e organizar a sociedade de forma tal a satisfazer as exigências de um mercado imobiliário foi parte vital do conceito utópico de uma economia de mercado (POLANY, 2012, p. 199).
}

Evidencia-se o interesse capitalista com a terra quando a transforma em mercadoria, separados em quatro estágios. Primeiro, pela comercialização da terra, na medida que considera a absolutização da propriedade privada. Segundo, pelo produção de matéria prima e alimentícia para atender as demandas internas e externas de produção. Terceiro, quando rompe barreiras atingindo mercados internacionalmente pela importação e exportação, importantes para o cálculo de balanças comerciais nacionais. Quarto, pela autoregulação do mercado, sem a interferência estatal que poderia estagnar esse processo de desenvolvimento 
econômico ideal. Nesse aspecto, fica o homem a mercê do capital, não só pela venda do trabalho e pela necessidade consumeristas, como anteriormente se explicou (POLANYI, 2012, p. 200-201).

Deste modo, em um primeiro aspecto, deve-se abordar a terra como uma dissociação do homem com a natureza motivada pelo capitalismo. O fenômeno da quantificação da terra, dá ensejo às primitivas e insustentáveis formas de produção humana, nas quais interesses econômicos, políticos e empresariais se sobrepõem à questão do vínculo com a terra de maneira vital, como se o meio ambiente pudesse ser utilizado como fonte inesgotável para a acumulação de capital.

Nessa perspectiva de dissociação, há necessidade de o homem se perceber como parte integrante do meio ambiente e não o ver como meio de obtenção do que deseja, sem pensar nas consequências que a sua utilização pode acarretar. Precisa se conscientizar que as ações econômicas devem respeitar o meio ambiente e os direitos das coletividades, o que o capital, por si, é incapaz de fazer. A tomada de consciência de que a degradação da terra pode atingir os direitos dos seres humanos à uma vida digna e saudável, tira a concepção da propriedade da terra e seu uso de uma pauta secundária, tornando-a eminentemente primordial (BALIM, 2012, p. 27-55).

Em um segundo aspecto, o homem vê sua liberdade cerceada, pela dificuldade de acesso à terra e a impotência frente aos mercados, uma vez que marginalizado da igualdade de oportunidades. O papel do interesse social caracterizado pelas lutas de classes e no âmbito agrário pelo enfrentamento do sistema por meio da posse campesina. E o Estado assume dois diferentes papéis: primeiro, na regulação do sistema condicionando a propriedade à uma função meramente produtiva, evidenciada pelas políticas tributárias ou de incentivo fiscal. E a segunda, regulando o mercado de trabalho, com o previsão de direitos sociais, fundamentando na busca de justeza social. No entanto, ambas medidas estatais, são voltadas para estabelecer um crescimento e fortalecimento do capitalismo, eis que em nenhuma destas, reitera-se a necessidade intrínseca do homem com a terra, como elemento de liberdade. Interessa ao Estado na verdade, o fomento ao mercado, seja por meio do trabalho ou consumo, seja pelo condição rentável da terra (POLANYI, 2012, p. 200).

Compreende-se o fenômeno de que a terra-matéria dentro da agricultura, cede espaço e transforma-se em terra-capital, em razão da financeirização e produtivismo (MULLER, 1989, p. 27-40). Por tal razão, o incentivo do capitalismo, na terra fora a intervenção interna e externa de financiamento ao agronegócio, dotado de umas perspectiva de enlace com a então vocação agrícola do país. O desenvolvimento da economia por meio do 
agronegócio cobra seu preço na medida determinada pelo capitalismo: a produção em larga escala para fluxo externo.

Tem-se, então, na verdade, um duplo financiamento da produçãodesenvolvimentista na esfera econômica do campo: o próprio Estado e o capital externo. $\mathrm{Na}$ ausência do Estado, a privada concorrência destes órgãos financiadores externos, manteria a produção nacional da terra voltado ao capital. De modo que, a visão do vínculo do homem com a terra, já não pode ser garantida somente pelo Estado, porque além de contrário ao próprio interesse e do capital, há agora novas forças de poder que determinam o desencadeamento das forças de trabalho e sociais do campo (MULLER, 1989, p. 42-58). Diante do quadro demostrado, há o desencadeamento de um processo de insuficiência de produção interna, aumento de pobreza e desencontro de interesses entre capital, Estado e sociedade (POLANYI, 2012, p. 202).

A previsão dos direitos fundamentais e sociais na Constituição Federal de 1988, e inclusive o da liberdade e de acesso à terra, não saiu do plano formal. A busca pela justiça social é um fundamento a ser encontrado, e mediante as normas constitucionais. Hoje, trata- se (e necessita-se) de um sistema capitalista popular, construído nos alicerces do Welfare State, que incorpore os trabalhadores em uma integração e cooperação para o desenvolvimento social e econômico. Promove-se a ideia de um sistema econômico mais justo no ponto de vista dos direitos fundamentais, e desapegado de conceitos tradicionais de capitalismo ou socialismo, retirando de ambos as contribuições para a evolução societária em um sentido de possibilidades (NUNES, 2008, p. 72-85). A solução adequada aos direitos fundamentais é o capitalismo nacional e associativo, que deve ser balizado no Estado mínimo de providência de direitos, cúmplice dos processos sociais de desenvolvimento humanitário e econômico (IANNI, 2004, p. 52-60).

O grande problema que se vislumbra é a ausência de identificação do homem com a terra. A terra transforma-se de elemento vital, para a terra-objeto de construção econômica e individual para o alcance de renda (lucros). O Estado, amparado pelo Direito para atender ao capitalismo, confundiu o indivíduo quanto a sua real relação com a terra. Seja como meio de subsistência, de moradia, de equilíbrio harmônico com a natureza e de respeito com as suas peculiaridades, há o confronto e a controvérsias de enfoques ambientais, políticos, econômicos, históricos e sociais nessa relação.

Olvidam-se, no entanto, todos: capitalismo, Estado, Direito e indivíduo da relação com a terra como um direito fundamental, coletivo e difuso. A propriedade privada, mesmo que determinada pelo capitalismo, deverá atender (e entender) a coletividade numa questão 
não somente ambiental de cuidado com as futuras gerações, mas também, de disseminação de igualdade de oportunidades. A efetividade da justiça social será concretizada, quando for absorvido o conceito de liberdade do indivíduo ligado ao conceito de que a propriedade deverá atender a comunidade. E, aqui, frisa-se a ineficiência da função socioambiental definida na Constituição Federal de 1988, eis que esta é meramente uma tática estatal de fundo capitalista, que não atende ao interesse social.

Então, a reforma agrária enquanto vista pelo aspecto capitalista define que o indivíduo continuará atendendo as demandas do capital. Agora, quando houver a compreensão da identificação do homem com a terra, balizado em preceitos de direitos comunitários e de liberdade de agir (produzir, consumir ou trabalhar), há de se confrontar o capital em um sistema de equilíbrio oportunizando condições fundamentais de vida à todos.

\subsection{Da Produção de Agrocombustíveis: A Face Cruel do Capitalismo}

Há suficiente divergência acerca dos fatores que influenciam a determinação do preço da terra. Desde o século XIX, estudiosos discutem a interferência causada pela quantidade de produto proveniente do trabalho da terra, isto é, o grau de produtividade, a renda da terra, bem como pelos níveis de oferta e demanda, nos preços dos imóveis rurais (BARROS, 2010, p. 17-31).

No caso do desenvolvimento de imóvel destinado à atividade agrícola, os riscos também são fatores relevantes, e não apenas aqueles inerentes a qualquer atividade (risco de mercado, risco operacional, risco de crédito e risco legal). Afinal, o sucesso da agricultura depende de fatores relativos a ela, tais como condições climáticas favoráveis, inexistência de pragas, e ainda se sujeita a condições de oferta e demanda dos produtos cultivados (BARROS, 2010, p. 32-34) ${ }^{1}$. No Brasil, a variação nos preços dos imóveis rurais é ainda determinada por outros fatores relacionados à instabilidade da economia. A terra, no cenário brasileiro, serve como reserva de valor alternativa.

\footnotetext{
${ }^{1} \mathrm{O}$ autor divide os riscos inerentes à atividade agrícola da seguinte forma: $\mathrm{O}$ risco de preço corresponderia à variabilidade dos preços dos produtos e insumos agrícolas determinados de acordo com sua oferta e demanda em nível mundial. O risco de produção estaria associado à impossibilidade de atuação em etapa produtiva específica, tais como plantio ou colheita, envolvendo ainda a possibilidade de alterações na produtividade de determinada área em razão da combinação de variáveis relacionadas como o clima, pragas ou doenças. O risco de renda seria estabelecido pela correlação entre os riscos de preço e produção. O risco financeiro dar-se-ia segundo o comportamento dos mercados, dos fluxos de produção e do gerenciamento da atividade, que influenciam o acesso ao crédito e podem interferir nas taxas de juros, provocando variações no patrimônio líquido dos agricultores. O risco institucional relacionar-se-ia à atuação governamental concernente a elaboração de que interfiram no desenvolvimento da atividade.
} 
O crédito rural também exerceria influência sobre o preço dos imóveis rurais brasileiros, uma vez que, apesar de destinado ao desenvolvimento da atividade agrícola, ser utilizado como capital de modo geral. Os recursos obtidos são investidos na atividade mais lucrativa, independentemente de se relacionarem ou não com atividades agrícolas. Todavia, o crédito só é concedido a quem é proprietário de terras, o que redunda em aumento dos preços, pois eleva a demanda pelo bem. Ainda, a infraestrutura de produção e comercialização também afetam a rentabilidade e a expectativa a seu respeito. Facilidades para irrigação, transporte e a proximidade dos mercados consumidores fazem aumentar os preços em razão de apresentarem menores riscos quando do desenvolvimento da atividade produtiva (BARROS, 2010, p. 61-68).

É congruente o entendimento de que o preço final é ditado de acordo com a conjunção dos fatores que interferem na atividade agrícola e com a possibilidade de converter a terra em reserva de capital ${ }^{2}$.

No que tange aos efeitos causados pela produção de agrocombustíveis ainda não se pode avaliar de modo definitivo qual seria o grau de influência gerado pela produção ou pelo aumento da demanda, haja vista a formação do preço das terras depender de todos os outros fatores citados anteriormente. Todavia, tudo indica que a esperança de ganho proveniente das atividades relacionadas à produção de combustíveis que não tenham origem fóssil, provenientes de fontes renováveis é bastante para promover a elevação dos preços dos imóveis rurais.

O Brasil foi o pioneiro na utilização da gasolina adicionada de etanol. Baseados nesta

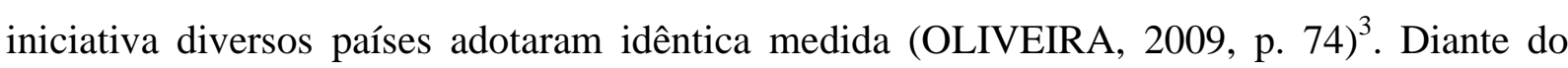
evidente interesse dos governos em diminuir a dependência do petróleo, não sem razão, os investidores voltaram seu interesse para o promissor o mercado de agrocombustíveis. Contudo, o investimento neste novo negócio requer não apenas capital e braços trabalhadores, mas depende fortemente da existência de recursos que, se não são finitos, não estão disponíveis a todos e têm capacidade limitada, além de dependerem de circunstâncias alheias à vontade do investidor.

\footnotetext{
${ }^{2}$ Não é possível afirmar que exista, na literatura especializada, um suporte teórico suficientemente sólido, que sugira a estrutura mais apropriada para modelar o mercado de terras. A grande complexidade com que as variáveis se correlacionam e como esta dinâmica se reflete na formação do preço da terra, faz com que muitas questões ainda permaneçam sem resposta (BARROS, 2010, p. 88).

${ }^{3}$ No Brasil permite-se que até $25 \%$ de cada litro de combustível seja composto por etanol. Nos Estados Unidos este percentual pode chegar a até $10 \%$ em alguns estados. A União Européia recomendava a mistura do equivalente a $2 \%$ até o ano de 2005, aumentando o porcentual para 5,75\% em 2010. Outros países como Canadá, Japão, Índia, Colômbia, Tailândia, China, Venezuela e Argentina também adotam ou estudam a mistura de etanol à gasolina.
} 
Esta expectativa, no que se relaciona aos agrocombustíveis, liga-se aos preços das commodities no mercado internacional, a sua produtividade, aos custos de sua produção, e à possibilidade de maximizar os ganhos por meio do uso de tecnologias empregadas na atividade de cultivo.

\footnotetext{
No curto prazo, a produtividade agrícola pode não sofrer grande influência da Agroenergia, mas, para médio e longo prazos, a expectativa de aumento na demanda por energias provenientes de fontes renováveis poderá alterar o direcionamento da pesquisa. Esta direção poderá contemplar o desenvolvimento de novas tecnologias e variedades mais produtivas do ponto de vista energético. Esta mudança pode alterar a expectativa de renda dos agentes envolvidos no setor produtivo, consequentemente, o preço da terra (BARROS, 2010, p. 122).
}

A alteração nos preços dos imóveis rurais tem reflexos nos preços dos alimentos, o que justifica a preocupação acerca da expansão do cultivo de gêneros agrícolas voltados a produção de agrocombustíveis. O que se desconhece é o grau de influência atribuído à produção destes combustíveis quando se verifica a formação dos preços dos imóveis rurais. No entanto, é importante verificar com mais detalhe as variáveis que tornam este investimento vantajoso.

O interesse pela produção de agrocombustíveis se justifica não somente pela premente impossibilidade de utilização de combustíveis fósseis ou pelos efeitos ambientais nocivos que decorrem da queima do petróleo e de seus derivados. As crises do petróleo durante os anos de 1970 continuam a servir de alerta aos países que muito dependem dos combustíveis fósseis. A redução da dependência se apresenta como medida necessária a diminuir a vulnerabilidade dos países em caso de instabilidade política e econômica no cenário internacional.

\footnotetext{
Sem menos importância, o esgotamento das reservas mundiais de matérias-primas fósseis, principalmente as de petróleo, somadas ao aumento das instabilidades geopolíticas, nas principais regiões produtoras, impulsionam, cada vez mais, o desenvolvimento destes novos modelos. Somam-se a este cenário os objetivos estratégicos e de segurança nacional de alguns países menos desprovidos destes recursos naturais, visando obter independência energética, ou, ao menos, diminuir a dependência atual, das fontes clássicas de energia fóssil (BARROS, 2010, p. 82).
}

O crescimento do interesse pela produção de agrocombustíveis também pode ser explicado pela manutenção artificial dos baixos níveis dos preços dos alimentos, provocados pela concessão de subsídios e imposição de barreiras tarifárias, que elevam os custos de produção da atividade agrícola.

Ademais, a incorporação de novos contingentes populacionais provenientes de países em desenvolvimento ao consumo mundial contribuiu para o crescimento da demanda mundial 
por commodities agrícolas. O aumento dos preços, neste viés, refletiria o realinhamento dos preços relativos, justificado pelo fato de ter aumentado a demanda por bens utilizados na produção agroindustrial ao mesmo tempo em que a demanda se encontra mais onerosa e reduzida (BARROS, 2010, p. 90-92).

\footnotetext{
Neste sentido, a elevação dos preços dos alimentos reflete um realinhamento dos "preços relativos", parcialmente explicado pelo crescimento da demanda por insumos agroindustriais, cuja oferta, restrita a um número reduzido de agentes, está mais cara e inflexibilizada, do ponto de vista de expansão, para atender o novo padrão de demanda (BARROS, 2010, p. 92).
}

Tal como ocorre no caso da definição dos preços das terras, é complicado identificar todos os fatores que causaram a elevação substancial no preço das commodities. O que se sabe é que esta elevação fez crescer também a expectativa de rentabilidade proveniente do investimento em agrocombustíveis, e consequentemente, provocou reflexos nos preços dos imóveis rurais (BARROS, 2010, p. 93).

Resta questionar se o investimento na produção de agrocombustíveis poderia comprometer a segurança alimentar e ainda, se é de fato, menos agressivo ao ambiente. Segundo Abramovay (2007), a despeito de haver inúmeros estudos baseados em dados empíricos que demonstram o avanço de lavouras destinadas à produção de agrocombustíveis sobre culturas voltadas ao abastecimento da população, é possível que se tenha conciliação entre elas sem provocar danos ambientais significativos. Destacam-se neste sentido o plantio de gêneros direcionados aos agrocombustíveis em áreas que já se encontram degradadas e a não utilização de única espécie neste mister.

\footnotetext{
[...] no padrão produtivo atual o conflito entre alimentos e energia é óbvio. No entanto, há dois elementos que podem alterar de forma significativa este cenário. Em primeiro lugar, podem ser melhor explorados sistemas de rotação entre oleaginosas - cujas propriedades fertilizantes do solo são conhecidas - com cereais. Além disso, muitas oleaginosas - é o caso da canola e também da soja - produzem, além do óleo, farelos ricos em proteínas e aproveitáveis na alimentação animal e ou humana (ABRAMOVAY, 2007).
}

Seria possível, por meio da implementação de mudanças na forma de cultivo, alterar a estrutura produtiva em que se baseia a obtenção de agrocombustíveis. Mas, para que isso aconteça é importante que considerar, outras variáveis além da simples busca pelo aumento na produtividade, sob o risco de provocar, de fato, sérios danos ambientais e sociais.

No caso da produção de etanol, todavia, sabe-se que a cana-de-açúcar é o vegetal que apresenta maiores índices de produtividade por hectare. Dificilmente, investidores deixariam de 
aplicar seu capital no cultivo de cana em nome da policultura, se não houver incentivo governamental que baste para tornar a atividade interessante aos olhos dos produtores.

De fato, a não interferência dos governos na produção de agrocombustíveis pode causar desequilíbrio na oferta de alimentos à população. Ainda que haja quantidade suficiente quando se examina o volume total, deve-se perceber os reflexos observados em âmbito regional. Com efeito, o problema que mais parece gerar preocupação é o fato de haver mais uma variável apta a provocar a elevação dos preços dos alimentos. Conforme já se considerou, o preço pago pela alimentação depende também do valor atribuído à terra, da rentabilidade gerada por determinado produto além de incontáveis fatores que determinam a produção (DEUTSCHE, 2011). Os agrocombustíveis se apresentam como novo fator a ser colocado no mesmo lado da balança em que se encontram as pragas e catástrofes.

No que tange à obtenção de etanol a partir da cana-de-açúcar, tem-se como centros produtivos os latifúndios monocultores o que torna a produção de agrocombustíveis incompatível com o desenvolvimento da agricultura familiar. Neste cenário os grandes produtores são os maiores beneficiados, não havendo, inicialmente, espaço para o produtor que cultiva a terra com o esforço de seus braços e ajuda de sua família. Todavia, quando se trata da produção de biodiesel, há iniciativas governamentais (Programa Nacional de Produção e Uso de Biodiesel - PNPB) que buscam fomentar a produção por pequenos agricultores, evitando a formação de extensas áreas de monocultivo, fomentando a utilização de diferentes matrizes energéticas e fortalecendo produtores familiares por meio do incremento de suas rendas (ABRAMOVAY; MAGALHÃES, 2007).

Merece destaque o fato de que a iniciativa deflagrada pelo PNPB recebeu apoio imediato por parte do movimento sindical de trabalhadores rurais e das empresas produtoras de biodiesel. Contudo, sabe-se que, não fosse a interferência do Estado, estabelecendo regras e condições no sentido de favorecer os pequenos agricultores, seria impossível estabelecer tal parceria (ABRAMOVAY; MAGALHÃES, 2007). De modo que, percebe-se que a anuência do Estado com a economia em sua face capitalista descaracteriza a relação do homem com a terra e o meio ambiente enquanto indivíduo e cidadão que carece da efetividade material dos preceitos constitucionais para o (des) envolvimento a partir do reconhecimento de indivíduo consigo, com o estado, sociedade e economia. Não somente como um dever programático da Constituição Federal 1988 mas como um compromisso com a justiça social pensando na construção de uma sociedade sólida e com autossuficiência alimentar. 


\subsection{Da Segurança e Soberania Alimentar: Dois Insitutos que se Complementam mas não se Confundem}

Contemporaneamente, de acordo com a Food and Agriculture Organization of the United Nations (FAO), "Existe segurança alimentar quando as pessoas têm, a todo momento, acesso físico e económico a alimentos seguros, nutritivos e suficientes para satisfazer as suas necessidades dietéticas e preferências alimentares, a fim de levarem uma vida activa e sã" (1996). O conceito de segurança alimentar deve ser analisado a partir do contexto de criação da FAO. O nascimento deste organismo internacional está intrinsecamente relacionado ao temor de que chegará a data em que não haverá alimentos suficientes e disponíveis à todos.

A FAO foi criada a partir das discussões iniciadas no seio do International Institute of Agriculture (IIA). O IIA tinha como principais objetivos a coleta e sistematização de informações e dados relacionados ao desenvolvimento da prática agrícola, além da elaboração de propostas direcionadas aos governos, para que se implantassem medidas que protegessem os interesses comuns dos agricultores e suas condições de vida (FAO, 1985, p. 5). Após a Crise de 1929, o setor agrícola sofreu os impactos da depressão, com a queda das importações e o colapso do comércio internacional, nesse sentido:

In the face of major financial difficulties, food-importing countries hastily erected tariff barriers and stepped up their domestic production. Trade collapsed: between 1929 and 1933, the wheat imports of the industrialized countries of Europe dropped by 60 percent (FAO, 1985, p. 6). ${ }^{4}$

A ideia de impossibilidade de fornecer alimentos à população em razão da baixa disponibilidade já impulsionava a discussão a respeito da segurança alimentar a partir da Primeira Guerra Mundial. Contudo, neste período, o conceito relacionava-se estreitamente à segurança nacional e à capacidade de cada país produzir os alimentos suficientes a abastecer sua população, reduzindo a vulnerabilidade a imposição de embargos decorrentes de razões políticas ou militares (RECINE, 2010).

\footnotetext{
4 Tradução livre: Ao enfrentarem grandes dificuldades financeiras, países importadores de alimentos rapidamente ergueram barreiras tarifárias e investiram no aumento da produção interna. Houve colapso do comércio. Entre 1929 e 1933, as importações de trigo proveniente de países industrializados da Europa caíram aproximadamente 60 por cento.
} 
Durante a terceira década do século $\mathrm{XX}$, houve período em que os excedentes produtivos dos agricultores de países desenvolvidos eram motivo de preocupação, pois não poderiam ser absorvidos pelo mercado em razão da conjuntura que se apresentava. Paralelamente, estudos a respeito da desnutrição conduziram à definição de requisitos necessários a uma dieta saudável, e à identificação de relevante número de pessoas desnutridas em países considerados desenvolvidos.

Em tal cenário, defendia-se o aumento do consumo em nome da boa nutrição. No entanto, a majoração do consumo contrariava as recomendações dos economistas que, para resolver a questão dos excedentes, propunham a redução na oferta de alimentos por meio de cortes na produção (CHONCHOL, 2005, p. 33-48).

Este paradoxo foi submetido à apreciação da Liga das Nações em 1935, concluiu-se que a resolução do problema de saúde pública por meio do consumo de alimentos necessários à boa nutrição, poderia também dar destino à crise da agricultura. Como resultado, formou-se a comissão responsável pela elaboração, em 1937, do relatório que despertou interesse do público e dos governos: The relation of nutrition to health, agriculture and economic policy.

Com o término da Segunda Guerra, foram iniciadas as discussões a respeito da possibilidade de provisão de alimentos nutritivos e suficientes a todas as pessoas em todos os lugares do mundo. Para que este objetivo fosse alcançado, estimava-se que seria necessário dobrar a quantidade de alimentos produzidos (FAO, 1985, p. 7).

Em 1943, quarenta e quatro países participaram da Conferência de Hot Springs, nos Estados Unidos, em que se decidiu pelo estabelecimento de uma organização internacional que tratasse da agricultura e da alimentação. Em 1945, criou-se a FAO. No documento produzido em Hot Springs, colocam-se como recomendações para solucionar as carências nutricionais de todas as pessoas por meio do incremento da produção, o uso equilibrado da indústria e da agricultura, o aumento do poder aquisitivo por meio do desenvolvimento industrial, o auxílio técnico e financeiro, a manutenção do equilíbrio nas balanças comerciais e a redução ou eliminação de barreiras comerciais entre os países (FAO, 1985, p. 10).

Tendo em vista a natureza destas recomendações, é de se constatar que não havia então grandes expectativas em relação a pequenos agricultores que produzissem alimentos voltados ao abastecimento de mercados locais. $\mathrm{O}$ foco se colocava nas negociações internacionais e na possibilidade de fornecer alimentos a países atingidos pelos males da fome utilizando os excedentes dos grandes produtores. A solução proposta pela FAO residia, basicamente, na facilitação do comércio entre as nações. Para que isso ocorresse, chegou-se a propor a elaboração de uma frente agrícola mundial, com a fixação de diretrizes comuns aos 
países membros. Diante da impossibilidade de estabelecer este tipo de ação, optou-se por incentivar a realização de acordos internacionais sobre commodities (FAO, 1985, p. 16).

Entre as décadas de 1960 e 1970, a Revolução Verde, refletia a preocupação em aumentar a produtividade. A comunidade científica concentrou esforços no desenvolvimento de variedades de plantas de alto rendimento, como trigo e arroz. Contudo, a despeito da elevação da oferta de alimentos, outros indicadores sociais demonstravam a queda da qualidade de vida do trabalhador rural (CHONCHOL, 2005, p. 33-34).

Outras consequências advieram da implantação do modelo produtivo propalado na Revolução Verde. Houve substituição de variedades de sementes e plantas nativas de regiões do Terceiro Mundo por outras que fossem economicamente mais lucrativas sob pretexto de baixo teor nutritivo das espécies utilizadas tradicionalmente pela população. Por não serem compatíveis com as variedades comercialmente desejáveis, as plantas empregadas de forma costumeira passaram a ser tratadas como pragas e combatidas com uso de agrotóxicos (SHIVA, 2003, p. $38-42)^{5}$.

Em 1983, o conceito de segurança alimentar foi reformulado pela FAO, que passou a considerar que haveria segurança alimentar quando todas as pessoas tivessem, a todo tempo, acesso físico e econômico a alimentação básica que lhes fosse necessária. Os objetivos específicos de uma política de segurança alimentar mundial estariam relacionados à produção em países de baixa renda, manutenção dos níveis dos estoques e facilitação do acesso de povos necessitados aos alimentos (FAO, 1985, p. 25).

A partir dos anos 1990, o debate a respeito da segurança alimentar foi retomado em razão do temor de que condições ecológicas como o aquecimento do planeta, o desmatamento de florestas tropicais e a erosão genética poderiam ameaçar a disponibilidade de alimentos. Além disso, passou-se a considerar a influência de questões políticas no abastecimento, já que algumas regiões (América Latina e Caribe) não obtiveram muito sucesso no incremento da oferta de alimentos ou tiveram sua disponibilidade reduzida, como ocorreu na África Subsaariana.

Em 1996, quando foi publicada a Declaração de Roma sobre Segurança Alimentar, a FAO reconheceu a pobreza, a existência de conflitos, terrorismo, corrupção e degradação do ambiente como causas de insegurança alimentar. Houve o comprometimento dos signatários para empregar esforços suficientes a reduzir pela metade o contingente de pessoas famintas (FAO, 1996). No entanto, constatou-se que em 2009, um bilhão de pessoas padeciam com os

\footnotetext{
${ }^{5}$ A autora indiana cita, entre outros, o exemplo da batua, planta rica em vitamina A e de elevado valor nutricional, eliminada por meio do uso de herbicidas por prejudicar o cultivo de trigo.
} 
males causados pela fome (FAO, 2010, p. 8) e em 2010, havia no mundo 925 milhões de pessoas famintas (FAO. 2010, p. 4). Esta redução é atribuída à redução do preço dos alimentos e amenização da crise econômica de 2009. Todavia, a FAO reconhece que o número de afetados pela fome é bastante alto, e considera inaceitável o aumento da quantidade de pessoas que sofrem em virtude de fome estrutural. Questiona-se acerca das razões que ainda fazem da falta de alimentos um dos grandes problemas que afligem a humanidade:

\begin{abstract}
A fome não é tanto a conseqüência de uma produção alimentar insuficiente, como da marginalização econômica de certas populações. Consequientemente, a prioridade não é tanto aumentar a produção dos que já produzem muito, mas dar a todos os meios necessários para produzir (CHONCHOL, 2005, p. 34-35).
\end{abstract}

As políticas de segurança alimentar e de combate a fome constituem verdadeiramente importante iniciativa na busca pela amenização deste problema. No entanto, é possível considerar que o trabalho realizado pelas organizações internacionais dificilmente servirá para solucionar definitivamente os problemas de abastecimento.

De outra banda, temos a ideia de soberania alimentar defendida pelos movimentos sociais, que se opõem veementemente ao modelo de produção baseado no monocultivo de gêneros limitados em grandes extensões de terra. Para compreender o conceito é mister conhecer o contexto no qual se insere a formação da Via Campesina.

A Via Campesina é movimento internacional que agrega milhões de camponeses, pequenos e médios produtores, trabalhadores sem-terra, mulheres camponesas e povos indígenas, em nome da luta pela promoção da agricultura sustentável, pautada em valores como a justiça social e dignidade (LA VIA CAMPESINA, 2011). A Via Campesina foi fundada em 1993, a partir da reunião de representantes de trabalhadores camponeses dos quatro continentes, a fim de discutir políticas agrícolas, a expansão do agronegócio e estabelecer metas comuns aos pequenos produtores. Deste modo, a Via Campesina significaria a possibilidade de participar diretamente das decisões que afetassem a agricultura camponesa, e os trabalhadores que dela dependem. Contemporaneamente, o movimento goza de reconhecimento por parte da FAO e das Nações Unidas, que o consultam na qualidade de movimento social internacional (LA VIA CAMPESINA, 2011).

O florescer da Via Campesina se desenrola em um contexto de alteração no papel do Estado em relação ao campo, sobretudo na América Latina. A mudança na natureza da intervenção estatal na economia rural nas três últimas décadas do século XX redundou em novos desafios para os povos camponeses, forçando-os a reestruturar os movimentos sociais 
para alcançar níveis internacionais, baseando-se não somente na luta de classes, mas na identidade coletiva que compartilham seus integrantes (MARTÍNEZ-TORRES, 2010, p. 151). Assim:

\begin{abstract}
Mais do que um conceito Soberania Alimentar se transformou em uma bandeira política dos movimentos camponeses vinculados a Via Campesina, que a partir do debate conceitual evidenciam a distinção entre os dois projetos de agricultura: o do agronegócio e o do campesinato, que possui lógicas produtivas e objetivos antagônicos (CAMPOS, 2007, p. 8).
\end{abstract}

A política de substituição de importações de produtos industrializados. Para possibilitar o desenvolvimento das indústrias nacionais, os governos propuseram políticas de preços mínimos que se prestassem a reduzir os gastos dos trabalhadores urbanos com alimentação, permitindo-lhes adquirir produtos industrializados da recém-formada indústria nacional. Esta política, contudo, não teve resultados positivos para os trabalhadores rurais, uma vez que a manutenção dos baixos preços dos alimentos serviu para sacramentar a pobreza no meio rural (MARTÍNEZ-TORRES, 2010, p. 151-152). O real interesse era permitir a transferência dos excedentes produzidos em áreas rurais para os centros urbanos e manter o processo de expansão da industrialização. A nova estrutura destes movimentos fundava-se na rejeição do clientelismo a fim de os desvincular dos interesses dos grupos urbanos aos quais se subordinavam. De modo que:

\begin{abstract}
To a greater or lesser extent these new organisations rejected the clientelism and corporatism of their forebears and refused to be subordinated to urban interests. These organisations called for a mixture of restoring improved versions of the state services cut back by neoliberalism and structural changes, such as agrarian reform and support for national markets, to favour peasant agriculture. They were, and remain, much more radical than the earlier generation of corporatist organisations, though it would be a gross exaggeration to say that they have eradicated clientelistic behaviours and attitudes, which vary from country to country and organisation to organisation (MARTÍNEZ-TORRES, 2010, p. 152-153) ${ }^{6}$.
\end{abstract}

Os camponeses defendem o usufruto individual da propriedade coletiva baseada em lógica de reciprocidade e produção voltada à subsistência. Desta forma, somente as relações externas às comunidades são regidas pela lógica mercantilista, já que dentro dos grupos camponeses, tal qual ocorre entre os povos indígenas, pratica-se a chamada economia moral em lugar da economia de mercado.

\footnotetext{
${ }^{6}$ Tradução livre: Em maior ou menor medida, estes novos movimentos sociais rejeitavam o clientelismo e o corporativismo de seus antecessores e se recusavam a se subordinar aos interesses urbanos. Estes grupos clamavam por um misto de restauração de versões melhores de serviços públicos prejudicados pela política neoliberal, tais como reforma agrária e apoio aos mercados nacionais, além de mudanças estruturais. Estes movimentos eram, e permanecem sendo, mais radicais do que a primeira geração de movimentos de trabalhadores. A despeito disso, seria exagero afirmar que posturas clientelistas foram erradicadas, uma vez que isto varia de acordo com a organização e com o país.
} 
À vista das discussões travadas pelos integrantes dos movimentos sociais camponeses, foram agregados outros grupos e questões relacionadas à política neoliberal desenvolvida nos países com aval da OMC, do Banco Mundial e da FAO. Grupos voltados à luta por direitos humanos, por direito à moradia, à terra, e à alimentação, entre outros, também passaram a fazer parte do movimento que clamava pela revisão do modelo de sociedade que se apresentava (MARTÍNEZ-TORRES, 2010, p. 155).

Assim, a Via Campesina resulta da conjunção de interesses partilhados por camponeses e outros grupos sociais a partir dos agrupamentos iniciais de natureza transnacional que mantinham relações entre si (MARTÍNEZ-TORRES, 2010, p. 156). E nesse contexto, constrói-se o conceito de soberania alimentar: na dissonância entre politicas agrícolas neoliberais e o interesse coletivo (CAMPOS, 2007). A ideia de que a agricultura camponesa está necessariamente associada a tempos antigos, que já não poderiam fazer parte da realidade contemporânea é contestada pela proposta da Via Campesina. Com efeito, o que pretendem os movimentos sociais camponeses é a experimentação de uma nova realidade social e econômica.

A concepção de soberania alimentar foi apresentada durante a Primeira Cúpula Mundial da Alimentação, realizada pela FAO em 1996, como paradigma alternativo no que diz respeito às questões concernentes à alimentação e à agricultura. Desde então, o conceito ganhou popularidade entre estudiosos de países do Sul e do Norte, sendo apontado como opção coerente e que compreende não apenas as necessidades relacionadas ao abastecimento, mas também as questões sociais afetas a elas.

\begin{abstract}
The Food Sovereignty proposal of La Via Campesina embodies the construction of new rights and the transformation of society as a whole. La Via Campesina works on many issues, but perhaps its central goal is to defend peasant life by constructing, proposing and defending this alternative model of food and agriculture (called Peoples' Food Sovereignty by La Via Campesina) (MARTÍNEZ-TORRES; ROSSET, 2010, p. 160) ${ }^{7}$.
\end{abstract}

De acordo com a Via Campesina, todos os países e todos os povos possuem direito e a capacidade suficiente para definir suas próprias políticas agrárias e alimentares. Portanto, abe a cada país e cada povo proteger seus mercados internos e formar reservas destinadas à agricultura, incluindo-se aí a possibilidade de fornecimento de subsídios aos pequenos produtores. Evidencia-se que os preços baixos estariam entre as maiores dificuldades a serem enfrentadas por produtores camponeses, motivo pelo qual seria importante aplicar de modo

\footnotetext{
${ }^{7}$ Tradução livre: A proposta de soberania alimentar da Via Campesina representa a construção de novos direitos e a transformação da sociedade como um todo. A Via campesina trabalha muitas questões, mas, talvez, seu principal objetivo seja defender o modo de vida camponês por meio da proposição, construção e defesa deste modelo alternativo de agricultura e alimentação (chamado de Soberania Alimentar dos Povos pela Via Campesina).
} 
eficaz políticas anti-monopolistas e controlar excedentes produtivos em países agroexporadores. Outrossim, seria preciso eliminar subsídios que se prestassem a manter o baixo nível de preços dos alimentos, a fim de praticar preços justos. Finalmente, não se poderia prescindir da realização de Reforma Agrária, e da fixação de limites fundiários mínimos e máximos, estabelecendo-se controle de sementes e de recursos naturais sem, no entanto, promover o patenteamento de sementes (MARTÍNEZ-TORRES, 2010, p. 160).

Assim, é válido transcrever o conceito de soberania alimentar proposto pela Via Campesina no Fórum Mundial sobre Soberania Alimentar, realizado em 2001.

\begin{abstract}
La soberanía alimentaria es la vía para erradicar el hambre y la malnutrición y garantizar la seguridad alimentaria duradera y sustentable para todos los pueblos Entendemos por soberanía alimentaria el derecho de los pueblos a definir sus propias políticas y estrategias sustentables de producción, distribución y consumo de alimentos que garanticen el derecho a la alimentación para toda la población, con base en la pequeña y mediana producción, respetando sus propias culturas y la diversidad de los modos campesinos, pesqueros e indígenas de producción agropecuaria, de comercialización y de gestión de los espacios rurales, en los cuales la mujer desempeña un papel fundamental(VIA CAMPESINA, 2001, p.4) ${ }^{8}$.
\end{abstract}

A Via Campesina defende que a fome e a desnutrição são causadas, não por desastres naturais, secas e acidentes geográficos, mas pelas políticas agrícolas e comerciais impostas por países desenvolvidos e suas corporações ansiosas por manter a hegemonia política, cultural, militar e econômica que ostentam. Destarte, a soberania alimentar se apresentaria como caminho alternativo bastante a garantir a segurança alimentar de todos e a dignidade daqueles que trabalham a terra com suas famílias (VIA CAMPESINA. 2001, p. 2). A não adoção de práticas que visem a soberania alimentar causaria danos à possibilidade de oferta de alimentos à população futuramente, além da diversidade e preservação cultural e alimentar dos povos (CAMPOS, 2007, p. 8). Cada povo deve ter controle autônomo de seu território, podendo nele desenvolver seu sistema produtivo e estabelecer a gestão dos recursos naturais e do espaço rural, a seleção de sementes e a difusão de conhecimentos tradicionais (VIA CAMPESINA, 2001, p. 4). O fato de a Via Campesina defender sistemas de produção diversificados, baseados na prática policultora e em técnicas ecologicamente sustentáveis, promoveu a adesão de movimentos ambientalistas à luta pela soberania alimentar.

\footnotetext{
${ }^{8}$ A soberania alimentar é a forma de erradicar a fome e a desnutrição e garantir a segurança alimentar duradoura e sustentável para todos os povos. Entendemos por soberania alimentar o direito de todos os povos de definir suas próprias políticas e estratégias sustentáveis de produção, distribuição e consumo de alimentos que garantam o direito à alimentação para toda população tendo como base a pequena e a média propriedade, respeitando a cultura e a diversidade dos costumes camponeses, ribeirinhos e indígenas de produção agropecuária, comercialização e gestão dos espaços rurais, nos quais a mulher desempenha papel fundamental.
} 
De acordo com o texto da Declaração Final do Fórum Mundial sobre Soberania Alimentar, além de promover a alteração das práticas produtivas, seria preciso interferir nos hábitos de consumo e "[...] con el establecimiento de políticas públicas que contribuyan a la construcción de sistemas alimentarios sustentables en el mundo" (VIA CAMPESINA, 2001, p. 6$)^{9}$.

Parte das críticas direcionadas ao modelo produtivo por ora sustentado diz respeito à proteção dispensada ao agronegócio em detrimento do produtor camponês. Ressaltam-se os efeitos nocivos causados pela produção monocultora em larga escala, ocupando grandes extensões territoriais, em descompasso com métodos de cultivo menos agressivos ao ambiente. A soberania alimentar e a mudança nas técnicas de cultivo por ela pregadas seriam economicamente viáveis, e garantiriam a preservação dos recursos para serem utilizados por gerações futuras (CAMPOS, 2007).

Por muito tempo, o modelo de produção do agronegócio representou o que havia de mais moderno e promissor, além de gerar expectativas acerca da possibilidade de resolução do problema do abastecimento da população mundial. A agricultura tradicional que utilizava baixos níveis de insumos e era baseada na mão-de-obra dos membros da família remetia à ideia de atraso a ser superado. A agricultura retrógrada seria modernizada por meio da implantação de máquinas agrícolas para agilizar o serviço e pelo uso de fertilizantes e agrotóxicos para aumentar os níveis de produtividade.

De fato, por algum tempo, houve aumento da produtividade proporcionado pelo modelo produtivo do high farming ${ }^{10}$. No entanto, com a redução dos custos de produção proporcionada pelo uso de tecnologias como o motor à vapor, entre outras, também foram reduzidos os preços dos produtos agrícolas, já afetados pela expansão produtiva pela qual passavam diversos países (VEIGA, 1996, p. 384). Ainda assim, a agricultura camponesa baseada no trabalho da família e voltada ao atendimento das necessidades comunitárias persistiu.

No Brasil, a agricultura tem como base o sistema de cultivo em latifúndios monocultores. A estrutura agrícola foi montada de modo a impedir que negros, índios e imigrantes não tivessem acesso à terra. A opção pela agricultura familiar nunca esteve entre as prioridades daqueles que elaboravam a política agrária do país. De fato, como bem

\footnotetext{
${ }^{9}$ Tradução livre: “[...] com estabelecimento de políticas públicas que contribuam para a construção de sistemas alimentares sustentáveis no mundo".

10 O termo era usado para indicar a nova onda tecnológica, dominada pela debulhadora a vapor e pela colhetadeira mecânica, ambas adotadas em larga escala no sul da Inglaterra.
} 
esclareceu Raymundo Faoro, tratava-se sempre de "mudar para manter" (MARTINS, 1996, p. $13)$.

Durante a ditadura, e durante o impulso em prol da nacionalização das indústrias houve notável incentivo direcionado à produção de cana-de-açúcar. Esta escolha não favoreceu o desenvolvimento da agricultura familiar. Ao contrário, os grandes fazendeiros avançaram ainda mais sobre as terras do sudeste do país, consolidando o sistema que privilegia o agronegócio em detrimento da agricultura camponesa. O Brasil escolheu o agronegócio quando outros países já haviam manifestado sua opção pelo sistema de pequena produção de natureza familiar. A escolha brasileira foi responsável pelo fluxo migratório direcionado aos centros urbanos e pela consagração da agricultura patronal e das estruturas fundiária e produtiva que lhes são inerentes.

Em outra vertente, a Via Campesina defende a ampliação do direito à informação acerca da qualidade e da origem dos alimentos, o que permitiria ao consumidor influenciar no controle qualitativo dos produtos postos no mercado (VIA CAMPESINA, 2001, p. 6). Em 1996, José Eli da Veiga já apontava a pressão exercida sobre os produtores agrícolas em virtude da questão ambiental como fator determinante nas escolhas adotadas por eles. Mais de dez anos após a publicação de seu texto, as tendências se apresentam cada vez mais concretas. Não apenas se exige comportamento ecologicamente sustentável por parte do produtor rural, como também de indústrias e de prestadores de serviços.

Desse modo, percebemos que há uma distinção abismal entre os conceitos de soberania alimentar e segurança alimentar. No entanto, ambos são complementares. E ainda, alicerces da construção de uma realidade que respeite o individuo e sua relação com a terra e o meio ambiente, fornecendo subsídios para a concretização de direitos fundamentais. A produção de agrocombustíveis em larga escala torna debilitada quaisquer outras formas de sustento, girando tudo em torno do capital, olvidando-se do combate a degradação ambiental e principalmente na produção e fornecimento de alimentos adequados em quantidade e qualidade a toda uma população, respeitando sua diversidade ambiental, cultural, social e geográfica (VEIGA, 1996, p. 388).

\section{CONCLUSÃO}

O homem tem relação com a terra de duas formas. A primeira coerente com o desenvolvimento capitalista, de onde retira da terra sua fonte de lucro. A segunda como uma 
relação vital de manutenção da vida. Nessa incongruência surge a ausência de (des)envolvimento dos indivíduos entre si e com o Estado. O capitalismo destrói as relações sociais como maneira de se fortificar.

Em favor do capitalismo, oprimis-e e marginaliza-se os indivíduos para uma vínculo com a terra meramente produtivo, olvidando da historicidade desses indivíduos na construção cultural de vinculo com a terra. Surge desta dissociação do homem com a terra, a reconstrução dos indivíduos da própria concepção de relação como parte integrante do meio ambiente. A dissociação acarreta uma confusão de conceitos éticos e morais, que faz com que o indivíduo enxergue a terra como meio de obtenção do que deseja, sem pensar nas consequências que a sua utilização pode acarretar.

A conscientização das ações econômicas deve respeitar o meio ambiente e os direitos das coletividades, o que o capital, por si, é incapaz de fazer. Imprescindível, neste momento, o papel do interesse social caracterizado pelos movimentos sociais campesinos. São neles que repousa a força para o ativismo Estatal. Sem os quais, ao Estado caberão dois papéis: primeiro, na regulação do sistema condicionando a propriedade à uma função meramente produtiva, evidenciada pelas políticas tributárias ou de incentivo fiscal; e, segundo, a previsão de direitos sociais, fundamentais programáticos em busca de uma justeza social para na verdade conter os insatisfeitos e condicioná-los à um mercado de trabalho fundado na expropriação da própria força laborativa. Assim, surge a necessidade do indivíduo de se integrar à sociedade em uma retomada de consciência política-cidadã.

A produção de agrocombustíveis assevera esse posicionamento trazido pelo capitalismo. A extensa produção descaracteriza a relação do homem com a terra e o meio ambiente, e intensifica a dificuldade de concretização de soberania e segurança alimentar.

Os movimentos campesinos e a FAO nesse aspecto, esmeram-se na produção de documentos e alertas a nível mundial. E embora, haja o comprometimento de diversos entes pouco se caminha para a concretização de direitos fundamentais. A segurança e soberania alimentar, além de preocupar-se com a qualidade e quantidade dos alimentos a nível mundial, perpassa a ideia de emancipação dos Estados, para a busca de identidade cultural e social dos indivíduos, e assim, a intensificação dos movimentos sociais na construção de uma nova realidade que concretize o (des)envolvimento de todos em prol de uma igualdade material.

Por óbvio, não há qualquer pretensão em esgotar tão vasto assunto. Espera-se superar as ideais que consagram o setor agrícola como área estratégica na garantia de desenvolvimento do país. Há de se pensar além da manutenção das cifras, e sim na consolidação cidadã por meio de um desenvolvimento social, político e econômico de todos 
os indivíduos. Afinal, de nada adiantarão máquinas, indústrias e dinheiro, se a população padecer com os males causados pela fome. A riqueza de um país de nada serve se não estiver refletida no bem-estar de seus habitantes.

O Direito, como instrumento de busca e realização da Justiça, não pode se afastar deste debate. Ao contrário, sua interferência determinará o sucesso ou a ruína da agricultura nacional, razão pela qual se faz necessário contribuir para que a questão tenha solução que aproveite aos brasileiros, assegurando-lhes alimento e dignidade.

\section{REFERÊNCIAS BIBLIOGRÁFICAS}

ABRAMOVAY, Ricardo; MAGALHÃES, Reginaldo. O acesso dos agricultores familiares aos mercados de biodiesel: parcerias entre grandes empresas e movimentos sociais. Londrina, $2007 . \quad$ Disponível em <http://www.fea.usp.br/feaecon//media/fck/File/Biodiesel_AIEA2_Portugues.pdf >. Acesso em: 15 jul. 2011.

ALTIERI, Miguel. Agroecologia, agricultura camponesa e soberania alimentar. Revista Nera. Tradução: Bruno L. Aretio-Aurtena e Sofia Lizarralde Oliver. Presidente Prudente, n.16, p. 22-32, Jan-jun. 2010.

BALIM, Ana Paula Cabral. Indivisibilidade socioambiental: Por uma visão integracionista entre os direitos sociais e a proteção ao meio ambiente. REDESG / Revista Direitos Emergentes na Sociedade Global. Disponível em: www.ufsm.br/redesg v. 1, n. 1, jan.jun/2012, p. 27-55.

BARROS, Fábio Renato Turquino. Os impactos da agroenergia no mercado de terras: dinâmica de preço e elasticidade de uso. São Paulo, 2010. Dissertação (Mestrado em Agroenergia) - Fundação Getúlio Vargas, Escola de Economia de São Paulo. Disponível em: <http://bibliotecadigital.fgv.br/dspace/bitstream/handle/10438/8281/65080100030.pdf?sequen ce=1>. Acesso em: 17 jun. 2011.

BRASIL. Ministério do Desenvolvimento Agrário. Mais alimentos: um plano da agricultura familiar para o Brasil. [S.1.], [2009 ou 2010]. Disponível em: <www.mda.gov.br/arquivos/1726917619.pdf>. Acesso em: em 27 abr. 2011.

CAMPOS, Christiane Senhorinha Soares; CAMPOS, Rosana Soares. Soberania alimentar como alternativa ao agronegócio no Brasil. Scripta Nova, Barcelona, v. XI, n. 245 (68), 1 ago. 2007. Disponível em: <http://www.ub.edu/geocrit/sn/sn-24568.htm>. Acesso em: 28 abr. 2011.

CFS. Final report of the thirty-sixth session of CFS, Roma, 11-16 out. 2010. Disponível em: <http://www.fao.org/fileadmin/templates/cfs/Docs0910/CFS36Docs/Final_Report/CFS36_Fi nal_Report_K9551_E.pdf>. Acesso em: 26 jul. 2011. 
CHONCHOL, Jacques. A soberania alimentar. Estudos Avançados, São Paulo, v. 55, n. 19, p. 33-48, Set-dez. 2005. Disponível em: <http://www.scielo.br/scielo.php?script=sci_arttext\&pid=S0103-40142005000300003>. Acesso em: 14 jul. 2011.

CONSEA. A segurança alimentar e nutricional e o direito humano à alimentação adequada no Brasil. Brasília, nov. 2010. Disponível em: $<$ http://www4.planalto.gov.br/consea/publicacoes/publiucacoes-arquivos/a-segurancaalimentar-e-nutricional-e-o-direito-humano-a-alimentacao-adequada-no-brasil >. Acesso em: 26 abr. 2011.

DEUTSCHE WELLE. Biocombustíveis, especulação e catástrofes elevam preço de alimentos. 13 mar. 2011. Disponível em: http://www.dw-world.de/dw/ article/0,,14905921,00.html. Acesso em: 15 jun. 2011.

FAO. Declaração de Roma sobre segurança alimentar mundial e Plano de Acção da Cimeira mundial da alimentação. Roma, 13-17 nov. 1996. Disponível em: <http://www.fao.org/DOCREP/003/W3613P/W3613P00.HTM>. Acesso em: 14 jul. 2011.

. FAO: the first 40 years. Roma, 1985.

The state of food insecurity in the world: addressing food insecurity in protracted crises. Roma, 2010. Disponível em: <http://www.fao.org/docrep/013/i1683e/i1683e.pdf>. Acesso em: 1 maio 2011.

FAORO, Raymundo. Os donos do poder: formação do patronato político brasileiro. 2. ed. rev. e aum. Porto Alegre: Editora Globo; São Paulo: Editora da Universidade de São Paulo, 1975. v. 1.

GIDDENS, Anthony. Capitalismo e moderna teoria social. $6^{\mathrm{a}}$ ed. Lisboa: Editorial Presença, 2005.

IANNI, Octavio. A ditadura do Grande Capital. Rio de Janeiro: Editora Civilização Brasileira, 1981.

. Pensamento social no Brasil. BAURU/SP:EDUSC, 2004.

IBGE (Brasil). Censo Agro 2006: IBGE revela retrato do Brasil agrário, [S.1], Set. 2009. Disponível em: <http://www.ibge.gov.br/home/presidencia/noticias/noticia_visualiza.php?id_noticia=1464\&i d_pagina=1>. Acesso em: 27 abr. 2011.

LA VIA CAMPESINA. La Via Campesina: international peasant's voice. Jakarta, Indonesia, 2011. Disponível em: <http://viacampesina.org/downloads/profiles/2011/BROCHURE-LVC2011-EN.pdf>. Acesso em: 9 nov. 2011.

MARÉS, Carlos Frederico. A função social da terra. Porto Alegre: Sergio Antonio Fabris Editor, 2003. 
MARTÍNEZ-TORRES, María Elena; ROSSET, Peter. La Vía Campesina: the birth and evolution of a transnational social movement. Journal of Peasant Studies, Londres, n. 37(1), p. 149-175, 22 jan. 2010. Disponível em: < http://www.tandfonline.com/doi/pdf/10.1080/03066150903498804>. Acesso em: 24 out. 2011.

MULLER, Geraldo. Complexo Agroindustrial e Modernização Agrária. São Paulo: Editora Hucitec, 1989.

NOVAIS, Fernando Antônio. O Brasil nos quadros do antigo sistema colonial. In: MOTA, Carlos Guilherme (Org.). Brasil em perspectiva. São Paulo: Difusão Européia do Livro, 1971. p. 47-63.

NUNES, António José Avelãs. Do Capitalismo e do Socialismo. Florianópolis: Fundação Boiteux, 2008.

OLIVEIRA, Izabel Cristina Carvalho de. Impactos econômicos e sociais dos biocombustíveis: a expansão da produção de cana-de-açúcar em minas gerais. Uberlândia, 2010. Dissertação (Mestrado em Economia) - Universidade Federal de Uberlândia, Instituto de Economia.

OLIVEIRA, Luiz César. Indústria do etanol no Brasil: uma estrutura de mercado em mudança. Curitiba, 2009. Dissertação (Mestrado em Desenvolvimento Econômico) Universidade Federal do Paraná, Departamento de Economia.

RECINE, Elisabetta. et. al. Direito humano à alimentação adequada no contexto da segurança alimentar e nutricional. Brasília: ABRANDH, 2010. Disponível em: <http://www.abrandh.org.br/download/20101101121244.pdf>. Acesso em: 19 jul. 2011.

RICARDO, David. Princípios de economia política e tributação. In: Os pensadores. São Paulo: Abril Cultural, 1978. p. 243-350.

ROSSET, Peter. Food Sovereignty and the Contemporary Food Crisis. Development, Reino Unido, n. 51(4), dez. 2008. Disponível em: <http://www.acciontierra.org/IMG/pdf/RossetDEVfoodcrisis.pdf>. Acesso em: 24 out. 2011.

. Food Sovereignty in Latin America: Confronting the 'New' Crisis. NACLA Report On The Americas. Nova York, maio-jun. 2009. Disponível em: < http://www.acaoterra.org/IMG/pdf/Food-Sovereignty-in-Latin-America.pdf $>$. Acesso em: 24 out. 2011.

SAUER, Sérgio; LEITE, Sérgio Pereira. Dinâmica fundiária e apropriação de terra por estrangeiros no Brasil. In: International Conference on Global Land Grabbing, 6-8 abr. 2011. Anais... Brighton: Land Deals Politics Initiative, Journal of Peasant Studies, 2011. Disponível em:

<http://www.iss.nl/content/download/24211/227524/version/2/file/53+Sauer_Pereira.pdf>.

Acesso em: 1 nov. 2011.

SHIVA, Vandana. Monoculturas da mente: perspectivas da biodiversidade e da biotecnologia. São Paulo: Gaia, 2003. 
THE WORLD BANK. Rising global interest in farmland: can it yield sustainable and equitable benefits? $\quad$ Set, $2010 . \quad$ Disponível <http://siteresources.worldbank.org/INTARD/Resources/ESW_Sept7_final_final.pdf >.

Acesso em: 4 abr. 2011.

VAZ, Lucio. Mais de 4 milhões de hectares estão sob comando de estrangeiros. Correio Brasiliense, Brasília, 9 jun. 2010. Disponível em: <http://www.correiobraziliense.com.br/app/noticia/brasil/2010/06/09/interna_brasil,196796/in dex.shtml>. Acesso em: 25 jun. 2010.

VIA CAMPESINA. Declaración Final del Foro Mundial sobre Soberanía Alimentaria. Havana, Cuba, 7 set. 2001. Disponível em: < http://www.fao.org/righttofood/kc/downloads/vl/docs/AH290_Sp.pdf>. Acesso em: 14 nov. 2011.

VEIGA, José Eli da. Agricultura familiar e sustentabilidade. Cadernos de Ciência \& Tecnologia. Brasília, v.13, n.3, p. 383-404, 1996. Disponível em: http://seer.sct.embrapa.br/index.php/cct/article/viewFile/9009/5115>. Acesso em: 11 jul. 2011.

VERGOPOULOS, Kostas. Capitalismo Disforme: o caso da agricultura no capitalismo. In: A Questão Agrária e o Capitalismo, AMIN e VERGOPOULOS, Samir, Kostas. $2^{\mathrm{a}}$ ed. Rio de Janeiro: Paz e Terra, 1986, p. 85-88

WALTERS-BAYER, Ann. et. al. Agricultura para o futuro: uma introdução à agricultura sustentável e de baixo uso de insumos externos. 2. ed., Rio de Janeiro: AS-PTA; Leusden, Holanda: ILEIA, 1999.

WORLD FOOD PROGRAMME. World must act now to avert catastrophe in horn of Africa. Roma, 25 jul. 2011. Disponível em: <http://www.wfp.org/stories/world-must-act- nowavert-catastrophe-horn-africa-says-wfp-executive-director>. Acesso em: 27 jul. 2011. 